the Chalky-Jurassic Boulder Clay fall into the Older Drift of the old classification, each separated by a hiatus of weathering and erosion. (2) The remaining glacial phases constitute the Newer Drift, of slight extent in the south but very strongly developed in the north and west? ${ }^{7}$. (3) The most marked interglacial phase followed the Older Drift. (4) In East Anglia, or parts thereof, the Chalky-Jurassic Boulder Clay (youngest member of the Older Drift) was the maximum glacial invasion: in northern England and South Wales the maximum was the Upper Chalky Drift (oldest member of the Newer Drift). The flourishing condition of British highland ice at this later episode is of particular interest.

At the present juncture few British geologists seem to be prepared to interpret the British chronology in terms of the Alpine sequence. This has been attempted on archæological evidence ${ }^{8}$, but there is a strong feeling that it is better to establish the initial sequence on its own merits, and not to introduce unnecessary complications until the second stageEuropean correlation--is attempted.

1 'T. Neville George, Geol. Mag., May 1933, pp. 208-232, and other recent contributions by the same author therein mentioned.

\& L. S. Palmer, Proc. Geol. Assoc., 42, 345, 361; 1931.

3 W. S. Bisat, Naturalist, July and October 1932: F. M. Trotter and S. E. Hollingworth, Geol. Mag., August 1932: 'A. Raistrick, and S. E. Hollingworth, Geol. Mag., August 1932: A. Raistrick, Trans. Northern Naturalists' Union, 1, Pt. 1, 1931, and Proc. Yorkshire Geol. Soc., 22, Pt. 1, November 1931. Dr. C. T. Trechmann is also taking an active part in these investigations.

J. Dolomon, Proc. Geol. Assoc, 43, 241-271; 1932. J. P. T. Burchell and J. Reid Moir, Man, February 1933.

For bibliography and correlation of this region, with specia reference to important work by Miss M. E. Tomlinson and F. W. Shotten, see some notes by the author of this review in Geol. Mag. January 1932.

${ }_{6}$ J. P. T. Burchell and J. Reîd Moir, ibid., and Nature, May 27 1933 , p. 756 . Authorities on this district like Messrs. Chandler, Dewey, and others are still considering special problems.

$?$ This was made especially clear in Mr. E. Dixon's correspondence with the writer.

8 M. C. Burkitt, Handbook of the Prehistoric and Protohistoric Sciences Congress, London, 1932. (Oxford University Press.) H. Breuil, Bull. Soc. Prehistorique Francaise, No. 12, 1932.

\title{
Statistical Weather Forecasting
}

$\mathrm{P}$ ROF. EMILE BOREL, the distinguished mathematician and former Minister of Marine in the French Government, gave a course of three lectures at the London School of Economics on November 14, 15 and 16, on "Quelques applications de la statistique aux previsions économiques (crises) et aux previsions meteorologiques". The first lecture, at which the French Ambassador presided, was devoted to a consideration of problems relating to the rate of interest and the devaluation of currency.

In his second and third lectures, Prof. Borel outlined a method of forecasting weather conditions. $\mathrm{He}$ first showed that, on the basis of observations at the Parc St. Maur Observatory near Paris over a period of fifty years, the greater the number of consecutive days upon which rain has fallen, the greater is the statistical probability that rain will fall on the next day. Likewise, the longer the duration of a rainless spell, the greater is the chance that the succeeding day will be rainless.

Taking the record of rainless days and of days of rain in the months October January in the fifty years, 1874-1923, Prof. Borel pointed out that rain fell on 52 per cent of the days. The probability that rain would fall on any one day between October 1 and January 31 is therefore $0 \cdot 52$. He has also tabulated the frequency of occurrence of spells of different durations of consecutive days of rain and of consecutive rainless days. The frequency of spells of one day of rain is 1,075 . The probability of rain falling on any day being 0.52 , the expected number of second successive days of rain is 559. The actual number is considerably greater, namely, 680 , corresponding to a probability of 0.63 that after a first day of rain, at least one more day of rain would occur. The probability that after two consecutive days of rain at least one more would ensue is still higher, namely, 0.66. Despite some irregularity due to insufficiency of numbers of observations, the probability that, after an $n$th day of rain, precipitation would occur on the following day, increases with the value of $n$. The irregularities disappear if the probabilities are averaged in groups of three, except for a fall in the probability curve at about the fourteenth day. Prof. Borel believes that there may possibly be a critical period in winter rainfall in Paris, in the sense that a change is more likely to occur after about fourteen consecutive days of rain than at any other time. Analysis of the frequencies of continuous spells of rainless days reveals a similar increasing probability of continuance with increasing duration, and a similar indication of a critical period at about the fourteenth day.

Examining frequencies of the number of days classified according to the quantity of rain falling during the 24 hours, Prof. Borel finds indications that the probability that, $n$ units of rain having fallen in a day, further rain would fall that day, increases with the value of $n$. He directed attention, however, to the fact that the units in which he has worked (millimetres) are arbitrary units, and different results might have been obtained if other units (say, inches) had been used.

Prof. Borel concluded by emphasising the desirability of basing further work on more abundant data than are yielded by the records of fifty years at a single meteorological station, as even this period gives small frequencies for spells of long duration and days of heavy rainfall.

F. B.

\section{Quantitative Analysis of Vegetation}

$\mathrm{S}^{\mathrm{E}}$ EVERAI, attempts have been made in recent years to apply quantitative methods to the analysis of vegetation. The present position of such investigations formed the subject of a discussion held at the Linnéan Society on November 23. The methods used may be divided into two classes : (i) those in which the object is to find a quantitative expression for the association as a whole; and (ii) those which are used to investigate the distribution of individual species within the association.

(i) Associations in Britain are conventionally described by a morphological method. The species are listed with approximate estimates of their relative abundance (dominant, frequent, rare, etc.). The variation from place to place in the association is described, and the description is illustrated by photo. 
graphs. This is, in fact, a close analogy of the description of a species in a flora. The question at issue is : Can the application of quantitative methods improve on these morphological methods of description ?

In Scandinavia a method for the analysis of vegetation is in use based on the 'percentage frequency' technique of Raunkiaer. In this technique the association is sampled many times with a quadrat and the presence or absence of species noted. The species are then classified into those which occur in 90-100 per cent of the quadrats, $80-90$ per cent, and so on. These values are known as the percentage frequencies. When the numbers of species in each frequency class are plotted against the classes, a frequency curve which is generally U-shaped is obtained. This U-shaped distribution is considered to be characteristic of the species composing a homogeneous community; that is, in such a community many species occur in $90-100$ per cent of the quadrats, many in $0-10$ per cent, and few in the intermediate classes. The U-shaped distribution becomes L-shaped or I-shaped according to the size of quadrat used but it is never a normal distribution. Does the reason for this abnormality lie in the method or in the vegetation itself ?

The answer to this question is given by a comparison of the percentage frequency obtained with the reality measured, that is, the number of individuals per unit area (density). The relation between these values is not linear but logarithmic. The classes in the percentage frequency distributions are therefore not of equal width. The 90 -100 per cent class includes a far greater range of densities than any other class. It is concluded, therefore, that the percentage frequency method of analysis is not a satisfactory measure of the distribution of species within an association, since the scale on which the frequencies are expressed is distorted.

The Uppsala school of ecologists describes an association from the number of 'constants' (for example, species in the $90-100$ per cent class) and the minimal area. Since their estimations are based on a percentage frequency technique, and for several other reasons, the method is of little value in describing associations. One must conclude, in fact, that the quality of an association has so far eluded any adequate quantitative expression, and the association must still be described in morphological terms.

(ii) Quantitative methods of the second class are employed to determine the distribution of individual species within the association. If a small quadrat is used and the chance of finding an individual is small, the quadrat throws may be classified into those in which no individual occurs, those in which one occurs, those in which two occur, and so on. If the individuals of the species are distributed at random, the successive frequencies follow the terms of a Poisson series, $e^{-m}, m e^{-m}, \frac{m^{2} e^{-m}}{2 !}$. . and from the 0 class the whole distribution may be calculated. Although the Poisson series is not strictly applicable to all such data, it serves as a test of 'randomness' of distribution. In pastures, it appears that the common species are often distributed at random, while the rare species are not. Wherever aggregation occurs, as for example where reproduction is vegetative, distribution is usually not at random. In making such determinations, it has been shown that a rectangular quadrat may be nearly twice as efficient as a square quadrat of the same area.
Quantitative methods have been used also to test the differential effect of some environmental factor on two species in an association. From the data collected from random samples, contingency tables may be prepared and the $\chi^{2}$ test applied.

In view of the attempt which is being made to standardise the methods of description of plant communities, it is important that the shortcomings and limitations of quantitative methods should be fully realised. It would appear that while quantitative methods are inadequate for the description of plant communities, they are valuable in studying the distribution of individual species within the community.

E. A.

\section{University and Educational Intelligence}

Cambridge.-Miss Mary Stuart Greg, of Hornby, Lancaster, has bequeathed $£ 500$ for the purpose of assisting agricultural research. The money is to be devoted to an investigation upon "the problem of sampling and the analysis of co-variance in plant populations at variable spatial intervals".

Mr. W. O. Henderson, Downing College, has been appointed University lecturer in the Department of Geography.

A University lectureship and a part-time University lectureship in the Faculty of Mathematics are vacant and appointments will be made in the Lent term. Candidates are requested to send their names, with any evidence of qualifications they may desire to submit, to Mr. M. H. A. Newman, Secretary to the Faculty Board of Mathematics, St. John's College, Cambridge, on or before December 16.

LoNDON.-Mr. R. W. Scarff has been appointed University reader in morbid anatomy and histology at Middlesex Hospital Medical School. He has been, since 1931, acting as senior pathological assistant in the Bland Sutton Institute of Pathology at that Medical School.

The title of emeritus professor of psychology in the University has been conferred on Dr. Beatrice Edgell, on her retirement from the professorship of psychology at Bedford College.

OxFORD.-On November 21, a sum not exceeding $£ 100$ was voted by Congregation towards the expenses of the Oxford University expedition to Ellesmere Land, north of Baffin Bay. At the same meeting of Congregation a grant of $£ 50$, in addition to an amount formerly allocated, was voted to the School of Rural Economy for an expedition to a district of the Southern Sudan with the view of investigating extreme conditions of drought and rainfall in their bearing on agricultural development.

The Right Hon. Lord Irwin, president of the Board of Education, has been elected Chancellor of the University, in succession to the late Lord Grey.

THe twenty-first election to Beit fellowships for scientific research will take place on July 13, 1934. Not more than three fellowships will be awarded, each of which will be of the annual value of $£ 250$ and will be tenable for two years at the Imperial College of Science and Technology. Further particulars can be obtained from the Rector, Imperial College, South Kensington, London, S.W.7. 